This is a self-archived version of an original article. This version may differ from the original in pagination and typographic details.

Author(s): Raippalinna, Liia-Maria

Title: Mobilising Consumers for Food Waste Reduction in Finnish Media Discourse

Year: 2020

Version: Accepted version (Final draft)

Copyright: (c) The Author, 2020

Rights: In Copyright

Rights url: http://rightsstatements.org/page//nC/1.0/?language=en

Please cite the original version:

Raippalinna, L.-M. (2020). Mobilising Consumers for Food Waste Reduction in Finnish Media Discourse. In E. Närvänen, N. Mesiranta, M. Mattila, \& A. Heikkinen (Eds.), Food Waste Management : Solving the Wicked Problem (pp. 289-317). Palgrave Macmillan. https://doi.org/10.1007/978-3-030-20561-4_11 


\title{
Mobilising Consumers for Food Waste Reduction in Finnish Media Discourse
}

Liia-Maria Raippalinna

University of Jyväskylä, Jyväskylä, Finland

\begin{abstract}
Raippalinna explores how consumers are mobilised for food waste reduction in media discourse. Food waste reduction initiatives are often criticised for putting the responsibility on individual consumers, but little research exists on mobilisation of consumers in actual contexts. Through critical discourse analysis of media texts, Raippalinna investigates how the food waste problem and consumers are constructed in relation to each other in the Finnish newspaper Helsingin Sanomat 2010-2017. The analysis demonstrates that the discourses of consumer mobilisation feature mostly as consumer education where consumers' role is to manage their own consumption and household practices. The theoretical framework combines governmentality studies approach and practice theoretical approach on sustainable consumption. Raippalinna discusses if and how media discourse can contribute to a transformation of food (waste) related practices.
\end{abstract}

\section{Keywords}

Food waste, Food waste reduction, Media discourse, Consumer, Consumer responsibility, Citizenship, Sustainable consumption, Critical discourse analysis, Intertextuality, Governmentality

\section{Introduction}

While the historical visibility or invisibility of waste and food waste in Western societies has been disputed in academia (Evans et al. 2013; O'Brien 2007; Åkesson 2012), the discursive visibility of food waste has undeniably increased enormously in the past ten years. Food waste has been perceived as an enormous sustainability problem due to the use of resources and the environmental impact related to food production and the global food system. In the European Union, a remarkable factor in constructing the food waste problem has been the political and scientific interest taken in the issue (Evans et al. 2013; Evans 2014). Many food waste-related governance initiatives in the EU have focused on changing consumer behaviour and reducing household food waste (Evans et al. 2013; Evans 2014; Gille 2013). In Finland, food waste became a subject of public discussion at the turn of the 2010s, as the Finnish Institute for Agriculture and Forestry (hereafter MTT) started their investigations into the theme. While food waste was investigated across the Finnish food chain, the research started from households. The problem of food waste was taken up in the media, which played a decisive role in introducing the issue to a wider audience and mobilising consumers for food waste reduction. 
It has been argued that the consumer-oriented approach taken in the EU not only serves the practical aim of reducing food waste but is attached to the political agenda of producing consumercitizens and aiming to relocate social and environmental responsibility on individual consumers (Gille 2013; also Evans 2014). However, there has been only little empirical research on how-and ifconsumers and consumer responsibility actually are constructed and mobilised in different contexts promoting food waste reduction. Evans et al. (2017) note that most critical approaches to sustainability initiatives "do not explicate the mechanism by which authorities and intermediaries attempt to responsibilise consumers" (p. 1399). They call for investigations on "the ways real and discursive figure of 'the consumer' features in the project of sustainable consumption" (p. 1400). Following Trentmann (2005), they claim that consumers should be recognised as a discursive category and subjectivity constructed together with food waste (p. 1400). The way people are framed as they are being mobilised-as consumers and as citizens - encourages certain kinds of action and frames their opportunities to exert influence (Bevir and Trentmann 2007; Soper and Trentmann 2008; Maniates 2002; Rumpala 2011).

In this chapter, I answer the call presented by Evans and colleagues by investigating how consumers are mobilised in media discourse: I analyse the discursive construction of food waste and consumers in the major Finnish newspaper Helsingin Sanomat 2010-2017. In current Western societies, media play a major role in constructing and mediating food-related trends and anxieties (Dickinson 2013; Halkier 2010; Karrebæk et al. 2018) as well as producing food practices and policies (Phillipov 2017). However, in the study of food waste reduction, the role of media in constructing the food waste problem and mobilising consumers remains largely unexplored (see however Närvänen et al. 2018; Thompson and Haigh 2017). Most research has focused on food waste reduction campaigns and, as Närvänen et al. (2018) point out, on the (short-term) success of campaigns, ignoring their content and message (e.g. Pearson et al. 2017; Pearson and Perera 2018). Research treating the media as a mere channel for consumer education offers a rather limited perspective on the role of media in mobilising consumers.

The role of media has been more fully acknowledged in the field of challenged, particularly sustainable, consumption (e.g. Halkier 2010; Podkalicka 2018; see also Goodman et al. 2017). Podkalicka (2018) proposes that in relation to sustainability and household consumption, media should be regarded as an actor, an intermediary and a culture. Regarding media as a culture emphasises that media representations are both constituted by and constitutive of cultural conceptions and practices related to food (waste); it contributes to sustaining (un)sustainable practices as well as transforming them. In this chapter, the view of media as culture, rather than channel, is emphasised.

In this chapter, I present three discourses in which food waste and consumer responsibility are most prominently constructed in Helsingin Sanomat. I adopt a critical discourse analytical approach in the analysis and make use of discourse analytical and intertextual methods. The theoretical framework combines governmentality studies approach and practice theoretical approach on sustainable consumption. I argue that in media discourse, responsibilising consumers is not just imposed by governance initiatives but derives from a wide range of sociocultural conceptions, discourses and social practices related to food, citizenship and consumption. I proceed to consider the potential for action and impact related to the framing of people as consumers vs. as citizens as they are mobilised in media discourse. Finally, I reflect on the practical implications of media discourse discussing if and how the media discourse can contribute to transforming practices in a more sustainable direction and lead to food waste reduction. The chapter contributes to the scholarly discussion on food waste reduction deriving from governmentality studies (Mcllvenny et al. 2016; Miller and Rose 2008) and other critical (e.g. practice theoretical) approaches to governance initiatives promoting behavioural change among (individual) consumers (see Evans et al. 2017; Gille 2013; Podkalicka 2018). 


\section{Consumer-Citizen and Sustainable Consumption}

Many sustainability initiatives, including food waste reduction initiatives, are based on approaches seeking behaviour change (Evans et al. 2017). These approaches, based on rational choice theory, seek and investigate sustainability in terms of (altering) consumer behaviour. They emphasise individual choice, based on available knowledge and individually held attitudes as the bases of un/sustainable consumption. The initiatives based on this approach rely on information sharing and value education as the bases of behavioural change. However, it has been shown that neither knowledge nor attitudes and values necessarily transform into sustainable practices (Bartiaux 2008; Shove 2010).

The behaviour change approach has met with criticism from practice theory approaches (see, e.g., Southerton and Evans 2017; Warde et al. 2017). Sustainability issues need to be resolved in terms of practices rather than individual behaviour. Methodological individualism, inherent in behaviour change approaches, renders the totality of practices elusive. According to Shove et al. (2012), social practices consist of meaning (ideas, discourses), competences (practical knowledge, routinised actions) and materials (materials, infrastructures) and in order to change them, changes are required in all these elements. The "strong version" insists that social, economic and technical structures, often treated as external factors obstructive or conducive to sustainable practices, are an integral part of practices, not exterior "conditions" of them (Van Vliet and Spaargaren 2017; Watson 2017). Food waste reduction is a particularly complicated issue as wastage is integrated into a variety of interlinked practices - both at level of everyday life (Evans 2014) and at the level of the global food system (Gille 2013). My focus in this chapter is on (media) discourse as part of the totality of practices.

Sustainability approaches grounded in governmentality studies share the critique presented by Shove and others claiming that current governance initiatives are often based on the neoliberal responsibilisation of consumers. According to them, many sustainability and environmental initiatives seek to hold individuals responsible and mobilise them to police their own conduct (Evans et al. 2017; also Lindegaard 2016; Mcllvenny et al. 2016; Rumpala 2011). The governmentality studies perspective calls for the analysis of the empirical forms that mobilising consumers takes in different sociocultural settings (Lindegaard 2016, p. 100; Mcllvenny et al. 2016, p. 29; Miller and Rose 2008, pp. 19-21). The approach puts the focus on individual and social bodies as objects of governance and investigates how they are produced as subjects in sustainable consumption.

Miller and Rose (2008) emphasise that social and economic problems (or environmental problems, such as food waste) are not preordained, but have to be constructed and made visible: to be governed, they need to be problematised. Framing a problem in a common language already implies a possible solution, technologies of intervention that allow authorities to manage the conduct of individuals or collectives. Governing takes place through different assemblages of actors and discourses, including the media: "issues and concerns have to be made to appear problematic, in different ways, different sites and different agents" (p. 14). Thus, framing the problem (food waste issue) and framing the subject of consumption (consumer-citizen) go hand in hand.

Studies on citizenship (see Bevir and Trentmann 2007; Soper and Trentmann 2008), as well as governmentality approaches to food consumption (Coveney 2006; Mayes 2014, 2017) ethical consumption (Barnett et al. 2010) and sustainable consumption (Rumpala 2011) raise the question how framing people as consumers or citizens determines their opportunities to act and exert influence. Focus on consumer behaviour may divert attention from big questions requiring major structural changes and political decisions (Rumpala 2011; also Maniates 2002). While consumerist 
initiatives have been criticised for discouraging the more traditional forms of citizenship and political participation, they are not necessarily mutually exclusive but co-occur in various forms of consumer-citizenship (Bevir and Trentmann 2007; Soper and Trentmann 2008).

\section{Data and Methods}

The data consist of 193 articles on food waste published in Helsingin Sanomat (hereafter HS) 20102017. HS, published in the Helsinki metropolitan area, is the major Finnish newspaper and the only daily newspaper in Finland with a nationwide readership. The data were collected from the newspaper's electronic archive using search term ruokahävikki, which is a core concept in the current Finnish food waste discourse (see the next section). The literal English translation would be food loss, but in most cases, the term refers to eatable food waste. The time period investigated (2010-2017) starts with the appearance of ruokahävikki in HS and is long enough to explore how the framing of the concept changes over time and as it travels between textual and sociocultural contexts. The data include articles from various genres and sections of the newspaper. These include, for example, local, domestic and foreign news, economics and science news, opinion, such as editorials, guest writers, columns and letters to the editor and articles published in sections related to food, home, city and lifestyle and in the weekly supplement Nyt [Now].

Methodologically, my analysis derives from critical discourse analysis (Fairclough 1992; Fairclough et al. 2011) and intertextual analysis (Blommaert 2005; Fairclough 1992). In critical discourse analysis, language use is analysed as consequential social action that takes place in particular textual, situational and sociocultural contexts. Following Fairclough (1992), I use a discourse (plural, discourses) to refer to "a particular way of constructing a subject-matter" (p. 128).

First, to identify the most significant discourses in which consumers are mobilised in the data I focused on frequently used expressions (terms, utterances and metaphors) and implicit assumptions that were made concerning the food waste issue and consumer's role in it. I identified three major discourses of consumer mobilisation: the scientific-political discourse, the home economics discourse and the discourse of new urban food culture. Second, to explicate these discourses, the following characteristics are analysed: (1) construction of the food waste problem, (2) construction of the consumer, (3) related social practices and sociocultural context. To analyse the construction of the food waste problem, I paid attention to how it was framed in the discourse and to the presentation of the reasons for and solutions to it. To analyse the construction of the consumer, I paid attention to the ways of framing the consumer's role in relation to the food waste problem (generation and reduction of food waste).

To contextualise the discourses in the wider sociocultural context, I looked for intertextual resources occurring in the data (Fairclough 1992; Blommaert 2005). By intertextual resources, I mean explicit intertextual references (manifest intertextuality) and subtle interdiscursive resources (constitutive intertextuality) (Fairclough 1992, pp. 100-136). By the latter, I mean particularly voices and discursive conventions, most importantly prior discourses utilised in the discourses of consumer mobilisation. The basic idea in intertextual analysis is that every text builds on features borrowed from previous ones; the intertextual and interdiscursive resources utilised in the production of texts, both constrain and constitute resources for creativity in text production. The way in which texts (or discourses) derive from various textual and discursive resources points towards the social structures and relationships established, maintained and reformed in the discourse (Fairclough 1992). For example, traditional home economics discourse, a central resource for one of the discourses presented here, is situated in the social practice of consumer education and home economics advice, aimed at producing responsible citizenship via everyday household practices. 


\section{Constructing Food Waste and Consumers}

The discourse on food waste gained momentum in HS in 2010, when MTT went public with their first research project on food waste, FOODSPILL 1 (2010-2012). Along with this research, a new concept, ruokahävikki, was introduced and established in public discussion, replacing the older term, ruokajäte, which literally means (inedible) food waste. The introduction of this new term indicates a discursive shift that occurs as wastage of food is perceived to cause sustainability problems in the food system; the matter of food waste [ruokajäte] was turned into an issue [ruokahävikki]. Earlier food waste [ruokajäte] was discussed as an environmental concern only in relation to (the environmental effects of) waste disposal; the generation of food waste was not discussed nor deemed problematic per se. The new term drew attention to loss of resources and environmental impact caused in the food production chain, inviting consumers-along with other actors-to take responsibility for the environmental impact of the food they waste. After the new concept was introduced, the use of other related terms, such as hävikkiruoka [surplus food, waste food], ylijäämäruoka [surplus food, excess food], ruokajäte [food waste], ruokaa roskiin [throwing food away, binning food], in HS decidedly increases, as the emerging discourse opens up space for terms and topics previously outside or in the margins of public discourse.

Scientific research and related consumer education materials have provided important discursive resources for a variety of other actors that discuss and promote food waste reduction in the data; many articles in the data refer directly or indirectly to MTT research. Even the use of the term ruokahävikki follows the definition proposed by MTT (Silvennoinen et al. 2012) as edible food that ends up being wasted instead of consumed. Although the term would apply to food loss as well as edible food waste, mostly consumer food waste is discussed in the data (on definitions of food waste see Papargyropoulou et al. 2014, p. 108). Texts found in the data are often build around one (or more) sectors/levels in the food system: Households are the most discussed sector (main focus in 53 articles) followed by retailers (30) and caterers and restaurants (23). Eight articles assign food waste to the food industry. A few articles consider food waste across the food system in a global perspective, connecting the food waste issue to other questions concerning food sufficiency and the sustainable use of agricultural resources.

Nevertheless, HS represents a polyphonic discourse on food waste that emerges as the concept of food waste ruokahävikki travels between sociocultural contexts deriving from different intertextual resources. The discourses of consumer mobilisation analysed here feature as overlapping "phases" in the food waste discourse. More importantly, they are attached to different sets of sociocultural practices taking place at different levels (areas) of society: The scientific- political discourse, featured in 105 articles, evolved around scientific research and political interests framing the problem at the level of society and the Finnish food chain. Having framed the (political) rationality of food waste reduction, the discourse was followed by the home economics discourse and the discourse of new urban food culture, featuring in 50 and 33 articles. The former delimits the problem and its solutions inside a household, and the latter situates the problem and its solutions in urban communities. Figure 11.1 describes the occurrence of these discourses in HS 2010-2017. It should be noted that several discourses of consumer mobilisation may feature in one article.

Fig. 11.1

Number of articles featuring the discourses of consumer mobilisation 


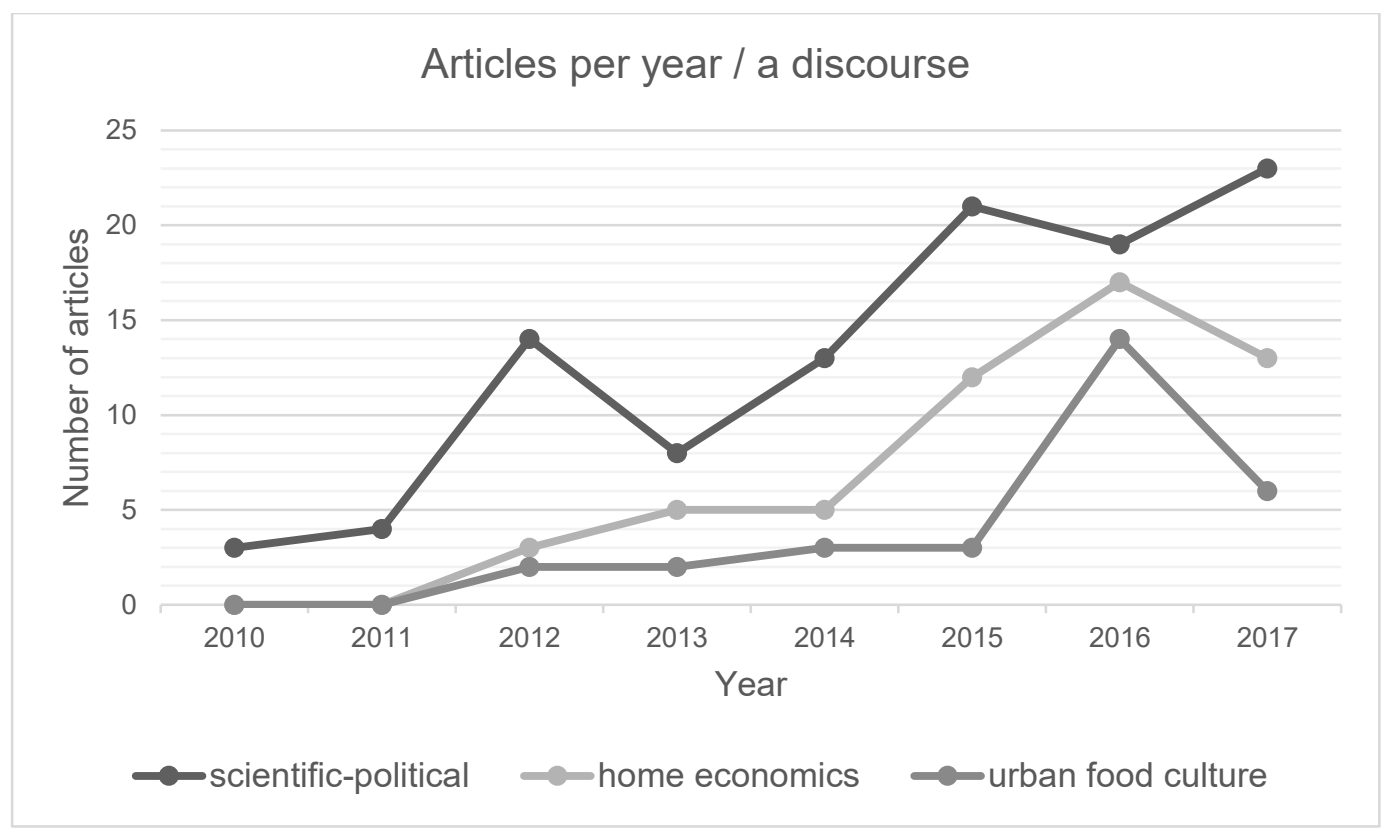

Scientific-Political Discourse

The ultimate objective of researching the food waste problem is its prevention. In order to efficiently plan measures to this end we need first to scrutinise the origins and causes of the problem. The waste is due above all to ignorance, a lack of knowledge, indifference and the decline in people's respect for food. There needs to be an extensive discussion in Finland about wasting food, what a serious matter it is and how it can be prevented. (03.11.2010, Opinion, Quest by MTT researchers, emphases added) (Quotations translated from Finnish)

The objective of FOODSPILL 1 was to evaluate the extent and environmental impact of the food waste generated in the Finnish food supply chain and to investigate the reasons for wasting food (Katajajuuri et al. 2014). Accordingly, the scientific-political discourse in the media operates on the level of the food system, particularly the Finnish food chain, and solutions to food waste problems are sought across society and in various parts of the food system. Whereas the general tone is that addressing the food waste question requires collaboration across the food supply chain, connections between different sectors seldom are properly illustrated in the media texts.

MTT studies originate in the political-scientific food waste discourse then predominant in the European Union (see Evans et al. 2013; Evans 2014). Connected to this wider European framework, the scientific-political discourse constructs food waste as a sustainability issue, in particular as an environmental concern. Food waste is represented as problematic because of the negative environmental effects of food production, above all climate change. The discourse crystallises in representations of the volume of food waste: "400 million kilos thrown away annually", "greenhouse gases equivalent to 100,000 cars". These figures constitute a point of reference for the material reality of food waste and testify to the magnitude of the problem. The fact that these representations are very similar to those found by Evans et al. (2017) in their study in the UK underlines the connectedness of this discourse to the European framework and previous food waste reduction initiatives. 
FOODSPILL 1 measured food waste sector by sector, including households, retailers, catering and restaurants, and food industry. Figures demonstrating wastage in different sectors and levels of the food chain are frequently repeated in the media discourse:

It was reported in Helsingin Sanomat that according to a study - 20 per cent of the food waste is from restaurants, 18 from retailers, 27 from the catering industry and 35 from households. Thus private households are the main source of waste. The choices they make could have the greatest effect on the amount of waste.

(15.08.2015, Opinion, a letter to the editor)

The waste occurring in the domestic food chain is under 400 kilos a year, according to an $\mathrm{MTT}$ estimate. The greatest wastage occurs in households, where every year large quantities of edible food are thrown away. (19.04.2012, Domestic)

Based on existing European research, MTT assumed households to constitute the most important source of food waste (see Silvennoinen et al. 2012). They were in the focus of media discourse even before the assumption was proved right by research results. Households were also established as the most important cause of food waste. Statements like "households are the biggest wasters", "30\% of all food waste is produced in households", "every Finn throws away $24 \mathrm{~kg}$ of food annually" or "Finnish consumers waste $20-30 \mathrm{~kg}$ food in a year" occur in the data. Reiterative representations of the share, amount and environmental effect of household food waste construct consumers as the actors responsible in relation to food waste and its environmental impact. Lack of knowledge and a decline in cultural respect for food are represented as the prime reason for wasting. Food waste is represented as a result of individual choices that consumers make based on their knowledge and values:

Each one of us can reduce the environmental burden considerably by paying attention to how they procure, process and prepare food. An effective and simple action for the good of the environment is not to throw food away. Food that gets thrown out burdens the environment more than the packaging, for example. Half a loaf of rye bread or a single slice of ham going into the rubbish bin causes a greater burden on the environment than making the packaging or waste disposal does. (03.07.2011, Opinion, Quest by MTT representatives, emphases added)

If a citizen wants to preserve Nature they should eat everything on their plate. A slice of ham in the rubbish bin burdens the environment more than the stuff the ham was wrapped in. (29.08.2011, Economy, emphases added)

It's about time for all of Finns to consider their own consumption practices, in order to reduce binning eatable food. (12.09.2014, Opinion, a letter to the editor, emphases added)

The discourse is featured as consumer education, oriented towards altering the individual performance of the consumer. It seeks to evoke consumer responsibility by illustrating how food waste generation (in households) is related to environmental issues and global food security. In the meantime, food waste reduction is offered as an easy solution to these complicated problems: whereas the environmental impact of different food items is hard to compare and not enough consistent information on their environmental impact is available to consumers, reducing food waste offers an effective and simple route to sustainable conduct, available to anyone. Major changes in lifestyle and consumption are not required, only cutting down on unnecessary wastage: "The most important thing is to avoid unnecessary wastage" (05.06.2014). 
The scientific-political discourse rendered food waste discursively visible by disseminating information on the volume and environmental impact of the food wasted in the Finnish food chain. Repetitive use of wastage figures in the newspaper resulted in their transformation into generally known facts establishing households as the major cause of wastage. The discourse calling for consumer responsibility was quickly taken up by various actors, such as political authorities, consumer educators and environmental organisations. It was even advocated as a "line of the paper", most evidently articulated in editorials. Taking care of one's own consumption behaviour is represented as a civic duty incumbent upon everyone.

\section{Home Economics Discourse}

The home economics discourse shifts the focus from constructing the food waste problem to solving it at household level. The focus is put on everyday practices and household skills. The discourse consists of three strains deriving from slightly different social practices and discursive resources: at the initial stage of the food waste discourse, consumers were educated by giving rather general advice, for example, to avoid food waste and plan grocery shopping. Later a more practical type of education, household advice, took up connected to food waste reduction campaigns. The third variation takes place in food and lifestyle journalism promoting a new kind of food culture along with easily accepted education and advice.

The first variation, consumer education, gives general advice on avoiding food waste while disseminating information on the food waste issue. Background assumptions concerning household food waste and consumer responsibility are derived from the scientific-political discourse. The discourse is employed by researchers, authorities and campaigners, as well as by media representatives:

Food gets thrown too easily into the rubbish. You get a long way when you learn two markings in the industry. The "use by" date is the date by which the product should be consumed. On the other hand the "best before" date does not mean that the product should already be discarded. It may no longer be at its best but it may still be fit for use. (06.09.2015b, Editorial)

The second variation derives from the more practical strand of household economics. In this discourse simple but often detailed advice is given on planning, purchasing, storing, preparing and re-using food. Promoting practical household management skills, the discourse recontextualises food waste in household economy and frames sustainable consumption within thrifty and reasonable consumption and good housekeeping. The discourse is employed by consumer educators, home economics organisations and others interested in food-related housekeeping practices, including journalists and individual citizens. In the following, a regional leader of the national home economics organisation, the Martha organisation, is interviewed: You should not go to either the supermarket or to the marketplace without a plan. "However tempting things may look, it is worthwhile considering what use you can make of the products.

Some of the vegetables and berries will keep for many days, and some will easily spoil", says [the leader of a regional Martha organisation]. By keeping in mind a few rules of thumb you can avoid unnecessarily wasting food. [Continues with the rules of thumb.] (22.07.2015, Food)

The third variation derives from food journalism and other forms of mediated food culture, including previous European food waste reduction campaigns (see Evans et al. 2017, p. 1404). With emphases 
on cooking and recipes, the discourse seeks to maintain and revitalise food culture -on the one hand, deriving from traditions, on the other by encouraging creativity and innovation. Leftover recipes are especially promoted as part of modern, sustainable cooking. Ordinary recipes turn into leftover recipes simply by adding advice to "hide" in leftovers or food about to go off:

Hint: Chili sin carne is like a fryup of potatoes or an omelette - that is, you can hide in it vegetables forgotten in the fridge. This is a way to reduce food waste and vegetables being thrown into the rubbish. Instead of Cheddar cheese you can grate in whatever was forgotten in the fridge. (09.04.2015, Food, recipe)

The home economics discourse contradicts ideal consumers with typical consumers in real situations. The ideal consumer makes a shopping list, buys wisely and knows how to use excess and leftover food but in real life, refrigerators are filled with food on the way to being wasted. Practices and values are interconnected, and the banal representations of household practices are coupled with an ideological dimension. Along with promoting non-waste behaviour, the discourse reproduces the traditional ideal of the thrifty, skilful consumer-housekeeper, devoted to serving the family with a proper home-cooked meal (see Ekström and Jonsson 2009). Food waste and wasteful practices may be represented as decay of food culture, especially of traditional values and skills. Past generations are represented as role models or sources of inspiration for today's consumers. The ideal consumer combines a modern lifestyle with the traditional ideology of household education and home cooking:

I have noticed that not many people eat their own packed lunches from home at work. It's so much more trendy and easier to buy something readymade from the shop or eat in the canteen... I always take my own packed lunch to work. It generally consists of leftovers from what I have made for my family. After the meal I put the leftovers in plastic boxes that I can grab from the fridge to take with me. - that way good homemade food is available at work and really very little is wasted.

(09.09.2016b, Opinion, a letter to the editor)

In the discourse, identities of thrifty, capable and creative householder-consumers are provided, and assumed, who show appreciation for food in their everyday practices. Individual consumers - the readers - are both addressed and represented as key actors in (household) food waste reduction. Consumers, struggling with everyday life, wasteful practices and the ambivalent feelings they arouse, are guided towards more sustainable practices by education and advice. A typical way of setting the scene for giving advice is to reconstruct a typical situation where food is about to be wasted: "Is there still half a lemon hanging about in the fridge?" (13.06.2017b).

The home economics discourse frames the food waste problem inside a household, putting emphases on everyday consumption practices. Consumers' role in food waste reduction is to learn to manage their consumption practices, and performance of non-wasteful practices is represented as being a part of good citizenship.

\section{The Discourse of New Urban Food Culture}

The third discourse, which I call new urban food culture, proposes practical means of tackling food waste in public space. The rationale of preventing and reducing food waste are introduced through representing waste reduction practices and services while they emerge in urban space, mostly in the city of Helsinki. They include establishing a restaurant serving "wasted food" a zero- waste bar and mobile applications that help to share, buy and donate leftover food from supermarkets, restaurants 
and private homes. The discourse also manifests in small articles and announcements about campaign happenings, which invite consumers to enjoy a free meal made of "waste food". Sharing and consuming excess happens in public and in wider social networks. Connected to locality, communality, sustainability and urban lifestyle, sharing and consuming excess creates and strengthens social relationships:

We want to change people's eating habits. Instead of going to the fast food place, we want them to fetch food from the neighbours. (01.04.2017, Economy)

In this discourse, ruokahävikki is coupled with another new concept hävikkiruoka [surplus food, waste food]. Whereas the former refers to food waste as a phenomenon, a problem and a process, the latter is used for food as a matter that is wasted or at risk of being wasted and for food as a matter that has been saved from being wasted. In this discourse, surplus discarded in one context is transformed into socially and culturally acceptable food in another. Food served in "food waste restaurants " is repeatedly represented as food that would have otherwise been wasted, thrown away, rejected et cetera. Recovering and consuming excess food is represented as "salvaging" food (05.09.2016) or "giving it another chance" (18.11.2016) or "another life" (04.08.2016), thus constructing this as ethical and sustainable conduct. New form of food culture is established on creating value from excess.

The culinary value of recovered food is evoked in textual and visual representations of ingredients and dishes as perfectly eatable as well as delicious. Cultural expectations are somewhat revised along with the practice of cooking. In the context of waste food restaurants, ad hoc creativity is encouraged, as available ingredients form the bases for cooking:

The helpings [in the restaurant] consist solely of food that would otherwise have gone to waste. That is food past its shelf life in the shops that would otherwise have been slung into the rubbish. - A casserole flavoured with mayonnaise has a soft flavour and the pieces of meat are tender. Afterwards I hear [from the cook] that most of the pieces of meat in the casserole are ox or pork tongue. - You cut your coat according to your cloth [says the cook]. (09.03.2016b Nyt [Now], weekly supplement)

The discourse of new urban food culture creates responsible consumption by introducing opportunities to take part in food waste reduction. Consumers participate in the reduction of food waste outside their own plate and household, as they consume and help others to consume food that would otherwise end up as waste. New audiences are approached by providing interesting products and convenient solutions for everyday food consumption, serving sustainability alongside. Appreciation for food is constructed in the practice of consuming waste food. On the other hand, participating provides an opportunity to perform individually held values and attitudes in public:

Could you taste that it had been made of leftovers [jämäruoka]? "No way", says [a customer] on a lunch break with a plate of meatballs. It's really good food and a fantastically good idea that you can recycle in this way and use up waste food [hävikkiruoka]. (04.04.2016b, City)

A cultural change is conducted by offering opportunities for sustainable food consumption in an urban environment. Food waste reduction is situated in a network connecting political, economic and civil society actors, and consumers are represented as potential innovators in tackling food waste. People behind the new services are represented as consumer-citizens actively contributing to the construction and reform of society: 
The idea for a waste food restaurant came from [name]. As a volunteer she collected food from shops whose shelf life was expiring and saw how vast quantities of eatable food were being thrown away... "We want to introduce the Amsterdam model into Helsinki." (11.12.2015, Nyt)

Media play a major role in constructing the new urban culture by featuring it in media discourse. Several articles on a single restaurant project were found in the data. Often different cases are drawn together in a single article as representations of the same cultural phenomenon. This serves to construct a general trend-or an emerging culture-out of single cases. The emerging local culture, steadily connected to the city of Helsinki, is set in an international context and represented as a global phenomenon. References are made to international examples in Berlin, Amsterdam, Stockholm, Paris, London and New York. Representing food waste reduction as a trendy urban phenomenon may help to reach new audiences, but it also risks to making it just another passing trend or an exclusive niche occupied by a knowledgeable urban middle class:

Better than basic meat in gravy is the new German urban middle class with its desire for novelty. The restaurant's [in Berlin] customers pay to dine on waste food. This is the foodsharing phenomenon; people share meals and ingredients and the ecological new urban way of life. For them the good life means that they can afford to consume in an ethical manner. (18.11.2016, Foreign)

Discussing food waste in terms of redistributing and consuming excess the discourse of new urban food culture constructs new modes of food consumption. Consumers are represented as a potential source of change as they are offered opportunities to participate in food waste reduction in urban communities.

\section{Discussion: Mobilising Consumer-Citizens in Media Discourse}

In $H S$, various actors and voices participate in the food waste discourse reproducing the representations of good citizen/consumer. The top-down governmentality of the scientific-political discourse meets the more horizontal forms that the mobilisation of consumers takes in the other discourses. While the scientific-political discourse framed food waste as a political issue, prior discursive recourses invoked in the media discourse contributed to the acceptance and escalation of the discourse and provided a cultural basis for holding consumers responsible. In the following, I discuss the discursive resources utilised in the discourses of consumer mobilisation and consider how the framing of people as responsible consumers and citizens in the discourses outlines their actions and possibilities to influence.

In media, the discourses mobilising consumers in food waste reduction are situated among a variety of other discourses that challenge consumption, seek behavioural change and put responsibility on individual consumers (Halkier 2010; Phillipov 2017). Food consumption has been a prominent issue in the two major discourses of contested consumption-the health and sustainability discourses. In this context, responsibility put on individual consumers makes sense. In the scientific-political discourse on food waste responsibilisation of consumers followed the line laid down in the sustainability discourse (see Evans et al. 2017), extending the notions of sustainability and consumer responsibility to the area of food consumption (household food waste), which until then had remained outside the mainstream political interest.

However, the discourse has roots beyond sustainability and contested consumption. The representations of wastage employed frequently throughout the discourse invoke traditional food- 
related norms and values. For instance, "wasting food", "throwing away food" and "binning food" are less practical representations of the act of wasting than metaphorical expressions resonating the traditional sociocultural norm of not throwing away food. A recurrent visual representation of breaking the norm in the data is a photograph of a biowaste bucket or a rubbish bin filled with food (waste). Wastage of food is often followed by feelings of shame (Evans 2014, p. 45). The wastage metaphors utilised in the media discourse feature as collective representations of shame and blame related food waste.

The traditional values also manifest in the home economics discourse ideal of good citizen. In Finland, domestic science and household economic organisations have educated people in thrifty and reasonable household practices for more than a century. They had a significant role in civic education and nation-building in the first half of the twentieth century (Heinonen 1998). Household work was framed as political as people were educated to perform good citizenship by exercising thrift and cleanliness in household practices. As the scientific-political discourse raised the food waste issue in the 2010s, food waste-related practices taking place in private kitchens were again framed as political and reconstructed as a form of responsible citizenship. While home economics offered both discursive resources and practical means to tackle the food waste problem in households, the scientific-political discourse on food waste provided home economics education with renewed political currency.

While sharing and consuming leftovers has traditionally been restricted to the private sphere of home and family (Cappellini and Parsons 2013), the discourse of new urban food culture constructs new modes of consumption based on sharing and consuming excess food in public. The wastage figures established in the scientific-political discourse lends this discourse its political rationality and traditional norms and values upheld in the home economics discourse constitute some of its sociocultural appeal. However, international food trends, food journalism and the overall mediatisation of food culture provide the discursive resources from which the discourse of new urban food culture derives in creating new forms of food consumption. Traditional food-related norms and values are updated to fit the new urban lifestyle and foodscape.

Both the scientific-political discourse and the home economics discourse revolve around individual performance of consumer responsibility. In the scientific-political discourse, citizens' role in food waste reduction is restricted to minimising their own food waste; people perform good citizenship by "doing their bit" and choosing to consume reasonably. Consumers are to manage their own conduct based on motivation and knowledge provided by experts and educators. In the home economics discourse, the consumer's role is above all to manage their own household practices, and these practices are reconstructed as a form of responsible citizenship. While good household skills are occasionally represented as an ability to resist the temptations of the consumer society and marketing, the discourse seeks to change consumer behaviour-not to transform the structures of economy and markets (see Mayes [2014] for health discourse and consumer choice).

Along with vertical household economics education, the home economics discourse displays horizontal consumer-to-consumer governmentality implying that responsible consumption can emerge through reforming food culture and consumption practices (Närvänen et al. 2018); consumers can participate in the reform by sharing practical tips and posing as role models for other consumers. In the discourse of new urban food culture, food waste reduction and the new modes of food consumption are represented in terms of opportunities rather than responsibilities. The discourse allocates responsibility, emphasising collaboration among different actors in the food system, but at the same time consumer-citizens are exhorted to perform active citizenship and entrepreneurship in the issue. 
Mostly the role of consumer remains restricted to managing their own consumption, and household practices and more or less local participation as consumer-citizens. While seeking to transform consumption behaviour and practices, the discourses of consumer mobilisation remain inside the structures that initially shape them. The discourses represent the "end of pipe" view (Alexander et al. 2013) on the food waste issue: pre-consumption food waste is clearly absent in the data, and drivers of food waste across the food system remain invisible in the contexts where consumer responsibility is built. The economic system, global trade, finance, production subsidies and other economic and political factors affecting food waste generation and sustainability are absent from the discourse (see Alexander et al. 2013; Gille 2013).

The relative absence of large-scale structural issues and solutions in the discourses mobilising consumers implies that they are treated outside the reach and interest of ordinary consumers. In the discourses analysed here, people are not framed as citizens having the opportunity (or responsibility) to participate and demand political action. They could be encouraged to call for extensive changes in the food system, but in the discourses analysed here any larger-scale questions concerning the food system are left to experts and politicians. Citizens are even told to focus on their own food waste and leave other sustainability issues to scientists and professionals.

In this chapter, I have contributed to the critical academic discussion on food waste and sustainability initiatives that put responsibility on individual consumer. I have done this by presenting a nuanced and empirically informed analysis of the forms that mobilising consumers takes in Helsingin Sanomat. Adopting governmentality and citizenship studies perspective, I investigated the framing of the food waste problem and the consumer in the discourses that mobilise consumers for food waste reduction. I demonstrated that consumer responsibility is not merely imposed by consumerist governance initiatives but derives from various discursive resources, such as traditional ideals related to good citizenship. However, I also pointed out that while the categories of consumer and citizen merge in the discourses of consumer mobilisation, the role assigned to the consumer-citizen is framed in terms of private consumption rather than active civic or political participation.

Focusing on discourses of consumer mobilisation leaves some remarkable discussions beyond the scope of this article, most importantly the discussions concerning retail food waste and its redistribution as food aid. From the perspective of citizenship, however, the construction of primary vs. secondary consumers taking place in this discussion would be an important research topic (see, e.g., Kortetmäki and Silvasti 2017). In addition, more investigation is needed into the allocation of responsibility and representation of structural drivers and solutions in media discourse on food waste.

\section{Practical Implications: From Media Discourse to Sustainable Practices?}

Practice theoretical approaches on sustainability emphasise normalisation as a prerequisite of successful transformation of social practices. A relevant question concerns whether media discourse will contribute to normalisation of non-waste practices and thus contribute to reducing food waste and increasing the sustainability of the food system. Although the reception and impact of media discourse are tricky to investigate (Halkier 2010; Podkalicka 2018), I offer some reflections on these issues based on current discussions in the field of sustainable consumption.

My analysis supports the argument that the valuation and appreciation of food, which many food waste reduction initiatives declare to be missing and seek to evoke, actually do persist in everyday cultural conceptions (Evans 2012). As Evans et al. (2013) suggest, these topics just did not fit the discursive domain until the sustainability discourse made food waste once again a public and political issue. Media discourse that started by lamenting the lack of values ultimately features their 
prevalence: while the framings of the food waste problem and its solutions may be disputed, the (economic, environmental, social and moral) importance of food waste reduction remains unchallenged in media discourse. As Evans (2014, p. 45) notes, the problem seems to be that food is wasted despite these widely held norms and values.

There exists a widely acknowledged gap in between values and practices, as knowledge, values or even widely held social norms do not necessarily materialise into sustainable practices. Especially practice theory approaches to sustainable consumption have questioned the feasibility of influencing individual behaviour by information and value education, maintaining that consumption is embedded in everyday practices (Evans 2014; Evans et al. 2017; Podkalicka 2018; Shove 2010; Southerton and Evans 2017; Watson 2017). Constituted by and constitutive of food-related practices media discourses both perpetuate the existing practices and have an ability to change them. Whether or not media discourses will contribute to changing food consumption practices on any larger scale depends on their ability to transform a wide range of food-related practices and normalise them as routinised everyday practices (see Evans 2014, pp. 95-96; Watson 2017). Strong practice theoretical approaches maintain that changing practices requires transforming the social and economic infrastructures, as they are essential part of the practices.

The scientific-political discourse and the home economics discourse feature as consumer education based on sharing knowledge, information and advice. While the latter does put the focus on household practices and the reorganisation of daily routines, ultimately both discourses feature methodological individualism as they seek to change and challenge consumer behaviour. Food waste prevention and reduction are constructed as a social norm, but little effort is made to truly abolish and replace the prevailing (unsustainable) social practices. The discourse of new urban food culture, however, is clearly involved in establishing new social practices, and HS is active in marketing the new practices to the public. Nevertheless, it risks constructing them as alternative instead of widely held practices spreading across society. In addition, as the discourse puts the focus on allocating and consuming excess, it provides no means to prevent it in the first place and leaves social, economic and material structures untouched.

Media discourse on food waste constructed food waste prevention as a social norm with political currency, but to normalise the non-waste practices beginning to emerge in the discourses would require going beyond consumer education, leftover recipes and representations on alternative modes of consumption. In the media, this would mean integrating food waste prevention and reduction into all aspects of mediated food culture, including recipes, commercials, restaurant reviews et cetera. Currently, food waste is framed as just another issue of contested consumption, detached from other food-related discourses; for instance, the data include several articles on a single food waste restaurant, but only one "conventional" restaurant review mentions food waste. In order to transform food-related practices, food-related discourses also need to be changed.

The discourses analysed here represent food waste as "excess" that can be eliminated, not as an elementary function of society or the food system (see O'Brien 2007; Reno 2015). As represented in the discourses, food waste can be reduced without having to give up anything (unlike in the case of reducing meat consumption, for example) and without having to change the social, economic and material (technological) structures in which the generation of food waste is embedded. Only one of the 193 articles in the data suggests reforming the global economic structures: according to this article, food is too cheap and sustainability problems require large-scale political solutions, for example, abandoning subsidies on meat production. Focusing on certain framings and solutions, the media discourse on food waste may mask other possible means of solving the food waste problem; in the bigger picture, it may mask other, possibly more effective means to tackle the sustainability issues of the global food system. 
As the major Finnish newspaper, $H S$ is influential in giving different voices a hearing. On the other hand, the paper quite uncritically reproduces the discourses provided by others and the given framings and solutions are rarely challenged. Stories are needed which illustrate food waste more ambitiously as part of the global food system, across national borders and at different levels of the food system. This way the social, economic and material infrastructures could be seen as an integral part of (un)sustainable practices, featured in individual performances of (ir)responsibility.

\section{Conclusions}

In this chapter, I investigated how consumers are mobilised in food waste reduction in the major Finnish newspaper, Helsingin Sanomat, during the period of 2010-2017. Building on governmentality studies, I analysed how the food waste problem and consumers were constructed in relation to each other in the data. I identified three major discourses in which consumers are mobilised: the scientific-political discourse, the home economics discourse and the discourse of new urban food culture.

The first two discourses frame food waste in the Finnish food chain and Finnish households. Focusing on household food waste, they feature as consumer education and underline individual consumers' responsibility in food waste reduction. The role of individual citizens is delimited to managing their own consumption and household practices. The third discourse concentrates on establishing new modes of food consumption based on consuming surplus food and represents food waste reduction in terms of opportunities instead of responsibilities. While giving consumers a more active role in participating the generation of new social practices, it risks constructing these practices as alternative modes of food consumption instead of widely held social practices. Both preconsumption food waste and (structural) drivers of food waste across the food chain remain invisible in the discourses and thus remain beyond consumers-citizens' reach and interest.

In order to contribute to a transformation of practices, the media discourse would need to overcome education, advice and international food trends and normalise food waste prevention and reduction by integrating them into all food-related discourses and genres of journalism. In addition, food waste should be illustrated as a part of the global food system, not as an excess that can be wiped out without transforming social, economic and material-technological structures.

\section{References}

Åkesson, L. (2012). Waste in overflow. In B. Czarniawska \& O. Löfgren (Eds.), Managing overflow in affluent societies (pp. 141-154). New York, NY: Routledge.

Alexander, C., Gregson, N., \& Gille, Z. (2013). Food waste. In A. Murcott, W. Belasco, \& P.

Jackson (Eds.), The handbook of food research (pp. 471-483). London: Bloomsbury.

Barnett, C., Cloke, P., \& Clarke, N. (2010). Globalizing responsibility: The political rationalities of ethical consumption. Hoboken, NJ: Wiley.

Bartiaux, F. (2008). Does environmental information overcome practice compartmentalization and change consumers' behaviours? Journal of Cleaner Production, 16, 1170-1180. 
Bevir, M., \& Trentmann, F. (2007). Introduction: Consumption and citizenship in the new governance. In. M. Bevir \& F. Trentmann (Eds.), Governance, consumers and citizens: Agency and resistance in contemporary politics (pp. 1-22). Basingstoke: Palgrave Macmillan.

Blommaert, J. (2005). Discourse: A critical introduction. Cambridge: Cambridge University Press.

Cappellini, B., \& Parsons, E. (2013). Practicing thrift at dinnertime: Mealtime leftovers, sacrifice and family membership. The Sociological Review, 60, 121-134.

Goodman, M. K., Johnston, J., Cairns, K. (2017). Food, media and space: The mediated biopolitics of eating. Geoforum, 84, 161-168.

Coveney, J. (2006). Food, morals and meaning: The pleasure and anxiety of eating (2nd ed.). Abingdon: Routledge.

Dickinson, R. (2013). Food and the media: Production, representation, and consumption. In A.

Murcott, W. Belasco, \& P. Jackson (Eds.), The handbook of food research (pp. 439-454). London: Bloomsbury.

Ekström, M. P., \& Jonsson, I. M. (2009). Family meals: Competence, cooking and company. In H. Janhonen-Abruquah \& P. Palojoki (Eds.), Food in contemporary society (pp. 23-28). Helsinki: University of Helsinki.

Evans, D. (2012). Beyond the throwaway society: Ordinary domestic practice and a sociological approach to household food waste. Sociology, 46(1), 41-56.

Evans, D. (2014). Food waste: Home consumption, material culture and everyday life. London: Bloomsbury Academic.

Evans, D., Campbell, H., \& Murcott, A. (2013). A brief pre-history of food waste and the social sciences. The Sociological Review, 60, 5-26.

Evans, D., Welch, D., \& Swaffield, J. (2017). Constructing and mobilizing 'the consumer':

Responsibility, consumption and the politics of sustainability. Environment and Planning A: Economy and Space, 49(6), 1396-1412.

Fairclough, N. (1992). Discourse and social change. Cambridge: Polity.

Fairclough, N., Mulderrig, J., \& Wodak, R. (2011). Critical discourse analysis. In T. A. Van Dijk (Ed.), Discourses studies: A multidisciplinary introduction (2nd ed., pp. 357-367). Thousand Oaks, CA: Sage.

Gille, Z. (2013). From risk to waste: Global food waste regimes. The Sociological Review, 60, 27-46.

Halkier, B. (2010). Consumption challenged: Food in medialised everyday lives. Farnham: Ashgate.

Heinonen, V. (1998). Talonpoikainen etiikka ja kulutuksen henki: Kotitalousneuvonnasta kuluttajapolitiikkaan 1900-luvun Suomessa [Peasant ethics and the spirit of consumption: From household advicing to consumer policy in the 20th century Finland]. Helsinki: Suomen historiallinen seura. 
Karrebæk, M. S., Riley, K. C., \& Cavanaugh, J. R. (2018). Food and language: Production, consumption, and circulation of meaning and value. Annual Review of Anthropology, 47(1), 17- 32.

Katajajuuri, J., Silvennoinen, K., Hartikainen, H., Heikkilä, L., \& Reinikainen, A. (2014). Food waste in the Finnish food chain. Journal of Cleaner Production, 73, 322-329.

Kortetmäki, T., \& Silvasti, T. (2017). Charitable food aid in a Nordic welfare state: A case forenvironmental and social injustice. In A. L. Matthies \& K. Närhi (Eds.), The ecosocial transition of societies: The contribution of social work and social policy (pp. 219-233). London: Routledge.

Lindegaard, L. B. (2016). The discursive intersection of the government of others and the government of self in the face of climate change. In P. Mcllvenny, J. Z. Klausen, \& L. B. Lindegaard (Eds.), Studies of discourse and governmentality (pp. 95-117). Amsterdam: John Benjamins Publishing.

Maniates, M. (2002). Individualization: Plant a tree, by a bike, save the world? In T. Princen, K. Conca, \& M. Maniates (Eds.), Confronting consumption (pp. 43-66). Cambridge, MA: The MIT Press.

Mayes, C. (2014). Governing through choice: Food labels and the confluence of food industry and public health discourse to create 'healthy consumers'. Social Theory \& Health, 12(4), 376-395.

Mayes, C. (2017). Food at the nexus of bioethics and biopolitics. In M. Rawlinson \& C. Ward (Eds.), The Routledge handbook of food ethics (pp. 167-177). London: Routledge.

Mcllvenny, P., Klausen, J. Z., \& Lindegaard, L. B. (Eds.). (2016). Studies of discourse andgovernmentality. Amsterdam: John Benjamins Publishing.

Miller, P., \& Rose, N. (2008). Governing the present: Administering economic, social and personal life. Oxford: Polity.

Närvänen, E., Mesiranta, N., Sutinen, U., \& Mattila, M. (2018). Creativity, aesthetics and ethics of food waste in social media campaigns. Journal of Cleaner Production, 195, 102-110.

O’Brien, M. (2007). A crises of waste: Understanding the rubbish society. London: Routledge.

Papargyropoulou, E., Lozano, R., Steinberger, J. K., Wright, N., \& bin Ujang, Z. (2014). The food waste hierarchy as a framework for the management of food surplus and food waste. Journal of Cleaner Production, 76, 106-115.

Pearson, D., Mirosa, M., Andrews, L., \& Kerr, G. (2017). Reframing communications that encourage individuals to reduce food waste. Communication Research and Practice, 3(2), 137-154.

Pearson, D., \& Perera, A. (2018). Reducing food waste: A practitioner guide identifying requirements for an integrated social marketing communication campaign. Social Marketing Quarterly, 24(1), 4557.

Phillipov, M. (2017). Becoming food: Eating media. Geoforum, 84, 241-242.

Podkalicka, A. (2018). Actor, intermediary, and context: Media in home renovation and consumption practice. Communication Research and Practice, 1-16.

https://doi.org/10.1080/22041451.2018.1507326

Reno, J. (2015). Waste and waste management. The Annual Review of Anthropology, 44, 553-572. 
Rumpala, Y. (2011). "Sustainable consumption" as a new phase in a governmentalization of consumption. Theory and Society, 40, 669-699.

Shove, E. (2010). Beyond the ABC: Climate change policy and theories of social change. Environment and Planning A: Economy and Space, 42(6), 1273-1285.

Shove, E., Pantzar, M., \& Watson, M. (2012). The dynamics of social practice: Everyday life and how it changes. London: Sage.

Silvennoinen, K., Koivupuro, H.-K, Katajajuuri J.-M., Jalkanen, L., \& Reinikainen, A. (2012).Ruokahävikki suomalaisessa ruokaketjussa. Foodspill 2010-2012 - hankkeen loppuraportti [Food waste in the Finnish food chain. Foodspill 2010-2012 report]. MTT Raportti 41. Jokioinen: MTT. http://www.mtt.fi/mttraportti/pdf/mttraportti41.pdf. Accessed on 12.3.2019.

Soper, K., \& Trentmann, F. (2008). Introduction: Consumption and citizenship in the new governance. In K. Soper \& F. Trentmann (Eds.), Citizenship and consumption (pp. 1-16). Basingstoke: Palgrave Macmillan.

Southerton, D., \& Evans, D. (2017). Consumption policies within different theoretical frameworks. In M. Keller, B. Halkier, T. Wilska, \& M. Thuringer (Eds.), Routledge handbook of consumption (pp. 204214). London: Routledge.

Thompson, K., \& Haigh, L. (2017). Representations of food waste in reality food television: An exploratory analysis of Ramsay's Kitchen Nightmares. Sustainability, 9(7), 1139.

Trentmann, F. (2005). Knowing consumer-Histories, identities, practices: An introduction. London: Birkbeck ePrints.

Van Vliet, B., \& Spaargaren, G. (2017). Structural conditions for and against sustainable ways of consuming. In M. Keller, B. Halkier, T. Wilska, \& M. Thuringer (Eds.), Routledge handbook of consumption (pp. 353-362). London: Routledge.

Warde, A., Welch, D., \& Paddock, J. (2017). Studying consumption through the lens of practice. In M. Keller, B. Halkier, T. Wilska, \& M. Thuringer (Eds.), Routledge handbook of consumption (pp. 25-35.) London: Routledge.

Watson, M. (2017). Sustainable consumption and changing practices. In M. Keller, B. Halkier, T. Wilska, \& M. Thuringer (Eds.), Routledge handbook of consumption (pp. 343-351). London: Routledge. 